\title{
Correction to: Impact of Size Distribution of Cell Model on the Effective Thermal Conductivity of Saturated Porous Media
}

\author{
Jianting Zhu ${ }^{1}$ (iD
}

Published online: 30 November 2021

(c) Springer Science+Business Media, LLC, part of Springer Nature 2021

\section{Correction to: International Journal of Thermophysics (2020) 41:34 https://doi.org/10.1007/s10765-020-2611-4}

The author discovered that the temperature gradient expression involved an approximation in the cell model adopted in the original version [1] after its publication. This approximation resulted in an additional " $l n$ " term in the effective thermal conductivity. After using the exact expression for the temperature gradient, the cell model was the same as the classical Maxwell model [2]. In majority of thermal conductivity and porosity combinations, the cell model adopted in [1] is close to the Maxwell model. In a certain small range of combinations, the additional term could cause unexpected results [3]. However, the setup of the cell model is physically sound. Based on this new understanding, the starting model in [1] should be the Maxwell model. As a result of better understanding, some equations and results in [1] should be updated. In particular, Eq. 2 in [1] should be:

$$
\frac{k_{e}}{k_{f}}=\frac{2 A+(A+3) y^{3}}{(A+3) y^{3}-A}
$$

Correspondingly, Eq. 21 in [1] should be:

$$
\frac{k_{e f f}}{k_{f}}=\int_{a}^{b} \frac{2 A+(A+3) y^{3}}{(A+3) y^{3}-A} f_{T Z}(y) d y
$$

The results presented in [1] can then be updated using the more accurate formulas in Eqs. 1 and 2. While limiting extreme of $a=1$ was used in most figures in

The original article can be found online at https://doi.org/10.1007/s10765-020-2611-4.

Jianting Zhu

jzhu5@uwyo.edu

1 Department of Civil and Architectural Engineering, University of Wyoming, Laramie, WY 82071, USA 
[1] to examine the maximum potential of pore size distribution impact, it should be clarified that the $a$ value in Fig. 3 of [1] was $a=1+\varepsilon\left[(1-\varepsilon)^{-1 / 3}-1\right]$, which means $(a-1) /\left[(1-\varepsilon)^{-1 / 3}-1\right]=\varepsilon$. In other words, the normalized starting value of y was directly related to the porosity. After updating the results in Fig. 3 in [1], the root mean square errors (RMSEs) of model predictions compared to the experimental data are $2.1526,1.8545,1.4055$, and 1.1990 for the uniform size cell model, $\mathrm{CS}=-0.5657, \mathrm{CS}=0.0$, and $\mathrm{CS}=0.5657$, respectively. In general, the model under-predicts the experimental results. The $\mathrm{k}_{\mathrm{f}}$ value used in Fig. 3 in [1] was from Fig. 8 in [4]. While quantitative results in Fig. 4 in [1] are slightly changed after updating, the main conclusions in [1] remain true. After updating Fig. 5 in [1], the RMSEs of the uniform cell model, negative skewness model $(\mathrm{CS}=-0.5657)$, zero skewness model $(\mathrm{CS}=0)$ and positive skewness model $(\mathrm{CS}=0.5657)$ are 1.3316 , $0.8153,1.5096$ and 2.3214 , respectively, which means the negative skewness model has the smallest RMSE. The discussion and conclusions associated with Fig. 6 in [1] remain true although quantitative values have changed slightly after updating. In summary, the main discussion points and conclusions in [1] remain true after updating the results based on the accurate starting model.

Acknowledgements The author would like to thank Dr. Hans Janssen at KU Leuven for pointing out issues in the model that was adopted as starting point in [1], which led to the more accurate equations and better understanding by the author. Dr. Janssen also pointed out vagueness of input parameters, which led to clarifications.

\section{References}

1. J. Zhu, Impact of size distribution of cell model on the effective thermal conductivity of saturated porous media. Int. J. Thermophys. 41, 34 (2020). https://doi.org/10.1007/s10765-020-2611-4

2. J.C. Maxwell, A Treatise on Electricity and Magnetism, vol. 1 (Claredon Press, Oxford, 1873), p. 365

3. H. Janssen, A critique on "A cell model of effective thermal conductivity for saturated porous media.” Int. J. Heat Mass Transf. 176, 121320 (2021). https://doi.org/10.1016/j.ijheatmasstransfer. 2021.121320

4. A. Revil, Thermal conductivity of unconsolidated sediments with geophysical applications. J. Geophys. Res. Solid Earth 105, 16749-16768 (2000). https://doi.org/10.1029/2000JB900043

Publisher's Note Springer Nature remains neutral with regard to jurisdictional claims in published maps and institutional affiliations. 